\title{
Impact of genetic variant of HIPK2 on the risk of severe radiation pneumonitis in lung cancer patients treated with radiation therapy
}

Yang Tang ${ }^{1 \dagger}$, Li Yang $^{2 \dagger}$, Wan Qin ${ }^{1}$, Min' Xiao Yi ${ }^{1}$, Bo Liu ${ }^{1}$ and Xiang ${ }^{\prime}$ Lin Yuan ${ }^{1 *}$

\begin{abstract}
Background: Homeodomain-interacting protein kinase 2 (HIPK2) has increasingly drawn attention as recent researches demonstrated its unique role in the regulation of multiple fundamental processes such as apoptosis, proliferation and DNA damage repair. Most importantly, HIPK2 was shown to play regulatory role in inflammation and influence the phenotype and activity of fibroblasts. In this study, we aimed to evaluate the impact of HIPK2 gene variant on risk of radiation pneumonitis for patients with pulmonary malignancies.
\end{abstract}

Methods: 169 lung cancer patients with radiotherapy were included in our prospective study and genotyped by Sanger Sequence method. Multivariable Cox hazard analysis and multiple testing were applied to estimate the hazard ratio (HR) and $95 \%$ confidence intervals (Cls) of all factors possibly related to the risk of radiation pneumonitis (RP).

Results: Patients with Mean Lung Dose (MLD) $\geq 15 \mathrm{~Gy}$, Lung $V_{20} \geq 24 \%$ had higher risk of RP $\geq$ grade 2 compared with those counterparts ( $\mathrm{HR}=1.888,95 \% \mathrm{Cl}: 1.186-3.004, P=0.007 ; \mathrm{HR}=2.126,95 \% \mathrm{Cl}: 1.338-3.378, P=0.001$, respectively). Importantly, CC genotype of HIPK2: rs2030712 were strongly related to an increased occurrence of RP $\geq$ grade 2 (HR= $2.146,95 \%$ Cl: $1.215-3.791, P=0.009$ ).

Conclusion: HIPK2: rs2030712 was found to be significantly related to RP of grade $\geq 2$ in our cohort, and may thus be one of the important predictors of severe RP before radiotherapy, if further validated in larger population.

Trial registration: Our study was prospective and observational. The research was registered in ClinicalTrials.gov database as NCT02490319.

Keywords: Radiation pneumonitis, Lung cancer, HIPK2, SNP

\section{Background}

Globally, lung cancer currently remains as the top one cause of cancer-related mortality. According to the latest statistical report, there are 2.1 million new lung cancer cases and 1.8 million deaths predicted globally in 2018, nearly close to 1 in 5 (18.4\%) of all cancer deaths [1]. Among all countries worldwide, China suffered from high rates of male lung cancer (above 40 per 100,000) in 2018. Radiotherapy (RT), with or without chemotherapy,

\footnotetext{
* Correspondence: xianglinyuantjmu@126.com

†Yang Tang and Li Yang contributed equally to this work.

${ }^{1}$ Department of Oncology, Tongji Hospital, Huazhong University of Science and Technology, Wuhan, Hubei Province, China

Full list of author information is available at the end of the article
}

still acts as the fundamental treatment for lung cancer patients. However, the efficacy of radiotherapy is restrained due to a series of RT-related complications that cause patients intolerance.

Radiation pneumonitis (RP) is a type of inflammation and subsequent fibrosis that occurs after irradiation, which is the most common complication and the major dose-limiting toxicity associated with radiotherapy. By limiting the radiation dose that can be applied and the size of the irradiated volume, RP hinders the tumorcontrolling effects of radiotherapy [2, 3]. Furthermore, poor quality of life or life-threatening symptoms can be caused by RP in $15-40 \%$ of all patients who are irradiated for lung cancer [4]. Therefore, reliable predictors

(c) The Author(s). 2020 Open Access This article is distributed under the terms of the Creative Commons Attribution 4.0 International License (http://creativecommons.org/licenses/by/4.0/), which permits unrestricted use, distribution, and reproduction in any medium, provided you give appropriate credit to the original author(s) and the source, provide a link to the Creative Commons license, and indicate if changes were made. The Creative Commons Public Domain Dedication waiver (http://creativecommons.org/publicdomain/zero/1.0/) applies to the data made available in this article, unless otherwise stated. 
for RP occurrence is of great value to maximize the therapeutic effects and to minimize its adverse effects of RT. In addition to the previous reported patient- and treatment-related factors [5], including Karnofsky performance status (KPS), chronic lung disease [6], smoking status, chemotherapy $[7,8]$, dosimetric parameters and plasma values of TGF $\beta[9,10]$, some genetic variants were recently found to be associated with the occurrence and development of RP [11-16].

Homeodomain-interacting protein kinase 2 (HIPK2) is a member of serine/threonine kinase family. HIPK2 plays important part in phosphorylation and interaction with a series of molecules involving development gene transcription and cellular responses to stress signals [17]. In addition, HIPK2 regulates multiple transcription factors functioning in different processes including differentiation, apoptosis and proliferation [18]. Recently, the function of HIPK2 in regulation of inflammation and fibrosis has drawn much attention. A study of idiopathic lung fibrosis (IPF) patients indicated that HIPK2 gene defect was found in fibroblastic foci and such defect may result in phenotypic and biological behavioral change of fibroblasts and myofibroblasts [19]. The results provided evidences that dysfunction of HIPK2 play significant role in disease progression and treatment resistance for IPF patients. However, up till now, the research on the function of HIPK2 in RP risk and pathogenesis is lacking. HIPK2 rs2030712 has been investigated as a potential risk factor of chronic kidney fibrotic disease occurrence and progression. Despite the fact that the study presented negative result [20], considering race disparities and different disease pathogenesis of RP, we selected rs2030712 as single nucleotide polymorphism (SNP) candidate for this study. In order to identify clinical valuable SNPs on RP occurrence and severity, in this study we explored the association between HIPK2 SNP rs2030712 with RP risk in our cohort.

\section{Methods}

\section{Patient population}

Our prospective study was registered in ClinicalTrials.gov database (NCT02490319). In brief, 190 lung cancer patients were initially enrolled. All patients were treated with radiation therapy at Tongji Hospital, Huazhong University of Science and Technology (Wuhan, Hubei Province, China) between 2009 and 2015. We included the patients with a radiation dose at least $45 \mathrm{~Gy}$, age $>18$ years old, KPS $>60$ and a life expectancy of at least 6 months. Patients with previous thoracic irradiation or severe cardiopulmonary diseases were excluded from our study. Of the 199 patients, 169 patients (114 with non-small cell lung cancer and 55 with small-cell lung cancer) were eventually included for the final genotyping analysis. Samples from 169 patients were genotyped by Sanger Sequencing for the SNP candidate. This study was approved by the Review Board of Tongji Hospital. Written informed consents were obtained from all patients for the use of their clinical information and for obtaining their blood and DNA.

\section{Treatment and follow-up}

All patients received radiotherapy with 6-MV X-rays from a linear accelerator (Elekta Synergy, Elekta, Sweden). The median total radiation dose was $56 \mathrm{~Gy}$ (range from 45 to $66 \mathrm{~Gy}$ ), with 1.5 to $2 \mathrm{~Gy}$ administered per radiation treatment. IMRT (intensity-modulated radiation therapy) was administered to $46.7 \%$ of patients $(n=79)$. Computed tomography simulation (CT/e, GE, Fairfield, Connecticut, USA) was performed before the RT treatment was planned. The target volumes and critical normal organs were delineated by the threedimensional planning system (Pinnacle Version 9.2). The baseline clinical characteristics and treatment details of the patients are shown in Table 1.

All patients enrolled in this study were examined during and one month after radiotherapy. Then, the patients were followed every three months for the first year and every six months thereafter. At each follow-up visits, all patients were asked to undergo a chest X-ray or CT and clinical information, including symptoms, was collected. RP was graded by two radiation oncologists (associate chief physician level required, with minimum 5 years of clinical experiences) according to the Common Terminology Criteria for Adverse Events 4.0 as follows: Grade 0 , no change; Grade 1, asymptomatic and diagnosed by radiographic findings only; Grade 2, symptomatic, not interfering with daily activities; Grade 3, symptomatic, interfering with daily activities or oxygen required; Grade 4, assisted ventilation required; Grade 5, fatal.

\section{Genotyping methods}

Genomic DNA was extracted with a PureLink Genomic DNA Mini Kit (Invitrogen, K1820-01) from peripheral blood. HIPK2: rs2030712 was selected as single SNP candidate in this study, and was genotyped by Sanger Sequencing method for samples from 169 patients included. The primer pairs for rs2030712 were F: 5' TGGAGATTTACAACACTCTAGGG -3'; R: 5' - ACAGAACTCACGTGTGCTTT -3 '. The 262 bp PCR products were then subjected to DNA sequencing to detect mutations.

\section{Statistical analysis}

The end point for this study was the development of $\mathrm{RP} \geq$ grade 2 . The time to the end point was calculated from the start of radiotherapy. Patients who did not experience $\mathrm{RP} \geq$ grade 2 within 12 months of $\mathrm{RT}$ were 
Table 1 Detailed clinical characteristics of the patients enrolled in this study $(N=169)$

\begin{tabular}{|c|c|c|}
\hline Characteristic & No. of Patients & $\%$ \\
\hline \multicolumn{3}{|l|}{ Sex } \\
\hline Male & 125 & 74.0 \\
\hline Female & 44 & 26.0 \\
\hline \multicolumn{3}{|l|}{ Age, years } \\
\hline Median & 58 & \\
\hline Range & $28-78$ & \\
\hline \multicolumn{3}{|l|}{ Histology } \\
\hline SCLC & 55 & 32.5 \\
\hline NSCLC & 114 & 67.5 \\
\hline \multicolumn{3}{|l|}{ Stage } \\
\hline |- I| & 24 & 10.2 \\
\hline III-IV & 145 & 85.8 \\
\hline \multicolumn{3}{|l|}{ KPS } \\
\hline $80-100$ & 123 & 72.6 \\
\hline$<80$ & 46 & 27.4 \\
\hline \multicolumn{3}{|l|}{ Smoking } \\
\hline Smoker & 106 & 62.0 \\
\hline Non-smoker & 63 & 38.0 \\
\hline \multicolumn{3}{|l|}{ Chemotherapy } \\
\hline Yes & 160 & 94.7 \\
\hline No & 9 & 5.3 \\
\hline \multicolumn{3}{|l|}{ CRT } \\
\hline Yes & 44 & 26.0 \\
\hline No & 125 & 74.0 \\
\hline \multicolumn{3}{|l|}{ Surgery } \\
\hline Yes & 86 & 50.9 \\
\hline No & 83 & 49.1 \\
\hline \multicolumn{3}{|l|}{ IMRT } \\
\hline Yes & 79 & 46.7 \\
\hline No & 90 & 53.3 \\
\hline \multicolumn{3}{|c|}{ Radiation dose (cGy) } \\
\hline Median & 5600 & \\
\hline Range & $4500-6600$ & \\
\hline \multicolumn{3}{|l|}{ MLD (cGy) } \\
\hline Median & 1368 & \\
\hline Range & 178-2017 & \\
\hline \multicolumn{3}{|l|}{$V_{20}$} \\
\hline Median & 24.82 & \\
\hline Range & $0-42.00$ & \\
\hline \multicolumn{3}{|l|}{ COPD } \\
\hline Yes & 19 & 11.2 \\
\hline No & 150 & 88.8 \\
\hline
\end{tabular}

Abbreviations: KPS Kamofsky performance status; CRT concurrent chemoradiation; IMRT intensity-modulated radiation therapy; MLD mean lung dose; $V_{20}$ volume of normal lung receiving $20 \mathrm{~Gy}$ or more radiation; COPD chronic obstructive pulmonary disease censored. SPSS 21.0 statistical software (SPSS, lnc., Chicago, IL, USA) was used for the statistically analysis. Patients were divided into groups according to their genotypes, and Cox proportional hazard analysis was applied to estimate the hazard ratio (HR) and 95\% confidence intervals (CIs) of all factors possibly related to the risk of RP. Moreover, multivariable Cox regression analysis was used for the adjustment of covariates. The influences of the genotypes on RP risk were assessed by Kaplan-Meier analysis and compared with log-rank tests.

\section{Results}

Patient characteristics and radiation pneumonitis

One hundred sixty-nine patients were included in this study with 125 males and 44 females. Their characteristics are listed in Table 1. The median age of the population was 58 years (range from 28 to 78 years); 114 patients had NSCLC, and 55 had SCLC. In the study cohort, $85.5 \%$ of patients had stage III-IV disease, $50.9 \%$ underwent surgery before RT, almost all patients (94.7\%) received induction chemotherapy followed by radiotherapy and $26.0 \%$ had concurrent chemoradiation. The median radiation dose was $56 \mathrm{~Gy}$ (range from 45 to $66 \mathrm{~Gy}$ ), the median mean lung dosage (MLD) was $13.68 \mathrm{~Gy}$ (range from 1.78 to $20.17 \mathrm{~Gy}$ ), and the median $\mathrm{V}_{20}$ was $24 \%$ (range from 0 to $42.00 \%)$.

Within 12 months of radiotherapy, 99 patients (58.6\%) suffered $R P \geq$ grade 2 . The associations between patient-, tumor- and therapy-related characteristics and $\mathrm{RP} \geq$ grade 2 are listed in Table 2. The univariable and multivariable analysis by Cox regression model revealed that MLD and $V_{20}$ was significantly related to $R P \geq$ grade 2 . Patients with elder age, MLD $\geq 15 \mathrm{~Gy}, \mathrm{~V}_{20} \geq 24 \%$ had higher risk of $\mathrm{RP} \geq$ grade 2 compared with those counterparts $(\mathrm{HR}=1.888,95 \% \mathrm{CI}: 1.186-3.004, P=0.007$; $\mathrm{HR}=2.126,95 \% \mathrm{CI}: 1.338-3.378, P=0.001$, respectively) (Table 2), which were consistent with the results of other publications.

\section{HIPK2 SNPs and RP}

HIPK2: rs2030712 was found to be significantly associated with the occurrence of $\mathrm{RP} \geq$ grade 2 (Table 3 ). Figure 1 is a plot of the RP-free survival percentage for $\mathrm{RP} \geq$ grade 2 for each genotype of HIPK2: rs2030712 determined by the Kaplan-Meier method. Patients with the CC genotype of HIPK2: rs2030712 had significantly higher risks of $\mathrm{RP} \geq$ grade 2 than patients with $\mathrm{CT}$ genotype $(P<0.0001)$. Furthermore, multiple Cox proportional hazard analyses with adjustments for all of the characteristics listed in Table 1 revealed that the CC genotype of HIPK2: rs2030712 were strongly related to a increased occurrence of $\mathrm{RP} \geq$ grade $2(\mathrm{HR}=2.146,95 \%$ CI: $1.215-3.791, P=0.009)$ (Table 3). 
Table 2 Association between patient-, tumor-, and therapy-related characteristics and Grade $\geq 2$ radiation pneumonitis $(N=169)$

\begin{tabular}{|c|c|c|c|c|c|c|}
\hline \multirow[t]{2}{*}{ Parameter } & \multicolumn{3}{|c|}{ Univariable Analysis } & \multicolumn{3}{|c|}{ Multivariable Analysis } \\
\hline & $\mathrm{HR}$ & $95 \% \mathrm{Cl}$ & $P$ & $H R$ & $95 \% \mathrm{Cl}$ & $P$ \\
\hline \multicolumn{7}{|l|}{ Sex } \\
\hline Female & 1 & & & 1 & & \\
\hline Male & 1.216 & $0.773-1.915$ & 0.398 & 1.379 & $0.758-2.511$ & 0.292 \\
\hline \multicolumn{7}{|l|}{ Age, years } \\
\hline$<58$ & 1 & & & 1 & & \\
\hline$\geq 58$ & 1.413 & $0.951-2.098$ & 0.087 & 1.541 & $0.997-2.383$ & 0.052 \\
\hline \multicolumn{7}{|l|}{ Histology } \\
\hline SCLC & 1 & & & 1 & & \\
\hline NSCLC & 1.195 & $0.791-1.804$ & 0.398 & 1.251 & $0.727-2.153$ & 0.418 \\
\hline \multicolumn{7}{|l|}{ Stage } \\
\hline$|-| \mid$ & 1 & & & 1 & & \\
\hline III-IV & 1.100 & $0.601-2.013$ & 0.758 & 1.132 & $0.593-2.163$ & 0.707 \\
\hline \multicolumn{7}{|l|}{ KPS } \\
\hline $80-100$ & 1 & & & 1 & & \\
\hline$<80$ & 1.341 & $0.877-2.052$ & 0.176 & 1.566 & $0.993-2.470$ & 0.054 \\
\hline \multicolumn{7}{|l|}{ Smoking } \\
\hline Smoker & 1 & & & 1 & & \\
\hline Nonsmoker & 0.926 & $0.619-1.386$ & 0.708 & 0.964 & $0.337-2.192$ & 0.435 \\
\hline \multicolumn{7}{|l|}{ Surgery } \\
\hline Yes & 1 & & & 1 & & \\
\hline No & 1.014 & $0.684-1.504$ & 0.945 & 0.690 & $0.390-1.223$ & 0.204 \\
\hline \multicolumn{7}{|l|}{ Chemotherapy } \\
\hline Yes & 1 & 1 & & 1 & & \\
\hline No & 0.500 & $0.203-1.233$ & 0.132 & 0.473 & $0.189-1.187$ & 0.111 \\
\hline \multicolumn{7}{|l|}{ CRT } \\
\hline Yes & 1 & & & 1 & & \\
\hline No & 0.843 & $0.529-1.344$ & 0.472 & 0.956 & $0.575-1.588$ & 0.861 \\
\hline \multicolumn{7}{|l|}{ IMRT } \\
\hline Yes & 1 & & & 1 & & \\
\hline No & 1.077 & $0.726-1.598$ & 0.712 & 1.098 & 0.710-1.699 & 0.675 \\
\hline \multicolumn{7}{|c|}{ Radiation dose, cGy } \\
\hline$<5600$ & 1 & & & 1 & & \\
\hline$\geq 5600$ & 1.083 & $0.729-1.610$ & 0.692 & 1.139 & $0.633-2.535$ & 0.737 \\
\hline \multicolumn{7}{|l|}{ MLD, cGy } \\
\hline$<1500$ & 1 & & & 1 & & \\
\hline$\geq 1500$ & 1.510 & $1.093-2.235$ & 0.045 & 1.888 & $1.186-3.004$ & 0.007 \\
\hline \multicolumn{7}{|l|}{ V20 } \\
\hline$<24 \%$ & 1 & & & 1 & & \\
\hline$\geq 24 \%$ & 1.730 & $1.138-2.631$ & 0.010 & 2.126 & $1.338-3.378$ & 0.001 \\
\hline \multicolumn{7}{|l|}{ COPD } \\
\hline Yes & 1 & & & 1 & & \\
\hline No & 0.639 & $0.246-1.661$ & 0.358 & 0.780 & $0.339-1.998$ & 0.472 \\
\hline
\end{tabular}


Table 3 Association between genotypes and Grade $\geq 2$ RP

\begin{tabular}{|c|c|c|c|c|c|c|c|c|}
\hline \multirow{2}{*}{$\begin{array}{l}\text { Polymorphism } \\
\text { and Genotype }\end{array}$} & \multirow{2}{*}{$\begin{array}{l}\text { No.of } \\
\text { event }\end{array}$} & \multirow{2}{*}{$\begin{array}{l}\text { No.of } \\
\text { total }\end{array}$} & \multicolumn{3}{|c|}{ Univariable analysis } & \multicolumn{3}{|c|}{ Multivariable analysis } \\
\hline & & & $\mathrm{HR}$ & $95 \% \mathrm{CL}$ & $P$ & $H R$ & $95 \% \mathrm{CL}$ & $P$ \\
\hline \multicolumn{9}{|c|}{ HIPK2: rs2030712 } \\
\hline$C T$ & 14 & 35 & 1 & & & 1 & & \\
\hline $\mathrm{CC}$ & 85 & 134 & 2.009 & $1.140-3.539$ & 0.016 & 2.146 & $1.215-3.791$ & 0.009 \\
\hline
\end{tabular}

NOTE: Multiple analyses in this table were adjusted for all the factors listed in Table 1

Abbreviations: $\mathrm{HR}$ hazard ratio; $\mathrm{Cl}$ confidence interval

Pc: $P$-value corrected by Benjamini and Hochberg False Discovery Rate correction

\section{HIPK2: rs2030712 and Dosimetric factors}

Patients were divided to four groups based on the dosimetric factors- $\mathrm{V}_{20}$ or MLD and HIPK2: rs2030712 genotypes in order to evaluate the impact of the HIPK2: rs2030712 genotypes on RP in different dosimetric groups. Patients with CC genotype of HIPK2: rs2030712 and MLD $\geq 15 \mathrm{~Gy}$ or $\mathrm{V} 20 \geq 24 \%$ had the highest risk of RP grade $\geq 2$ compared with other groups $(P<0.0001$ and $P<0.0001$, respectively, Fig. 2a, b). Interestingly, for the patients with HIPK2: rs2030712 CC genotype and MLD $<15$ Gy or V $20<24 \%$, they had even higher incidence of $\mathrm{RP} \geq$ grade 2 with the patients who received MLD more than $15 \mathrm{~Gy}$ or V20 more than 24\%, suggesting the dominant and independent role of HIPK2: rs2030712 genotypes in RP.

\section{Discussion}

In this study, HIPK2: rs2030712 were found for the first time to be significantly associated with the occurrence of $\mathrm{RP} \geq$ grade 2 . Patients with the CC genotype of HIPK2: rs2030712 had a significantly increased risk of RP after radiotherapy for lung cancer. We also discovered that

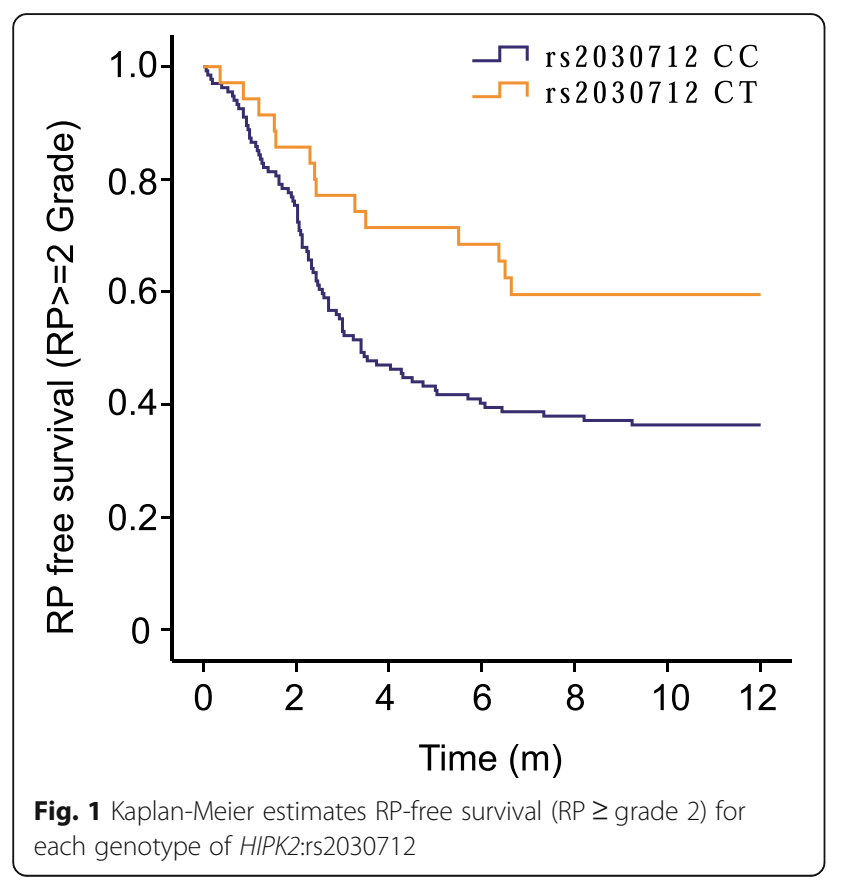

the association between HIPK2: rs2030712 and RP grade $\geq 2$ was independent of MLD and $V_{20}$.

The occurrences of $\mathrm{RP} \geq$ grade 2 were $58.6 \%$, which were similar to those reported previously. Due to the prospective nature of our study, the incidence rate of RP was relatively higher than in some retrospective studies. We also confirmed that age, MLD and $V_{20}$ was closely related to the risk of RP. In our cohort, patients with $M L D \geq 15 G y$ and $V_{20} \geq 24 \%$ had a greater risk of developing RP grade $\geq 2$, which verified the associations between the radiation dosimetric-related factors and the occurrence of RP.

As is well known that pro-inflammatory and fibrogenic cytokines induced by irradiation are involved in the pathogenesis of RP [21]. Our previous studies have already demonstrated that SNPs of several genes involving inflammation regulation are associated with RP risk [11-14]. However, the exact role that HIPK2 playing in tissue inflammation and fibrosis is largely unknown. Recent advances in kidney fibrotic disease indicated that the protein expression of HIPK2 was significantly elevated in human HIV - associated nephropathy patients [22]. In renal tubular epithelial cell model, study demonstrated that HIPK2 not only up-regulated expression of several pro-fibrotic cytokines, such as smooth muscle actin, fibronectin, collagen I, but also activated several pro-fibrotic and pro-inflammatory signal pathways including TGF- $\beta$ (transforming growth factor $\beta$ )-Smad3, Wnt-Notch and NF-kB pathways [23]. On the other hand, the role of HIPK2 in pulmonary fibrotic disease, especially in RP is much less clear. Results from study on idiopathic pulmonary fibrosis (IPF) patients demonstrated that HIPK2 expression in IPF-derived fibroblasts is significantly lower compared with normal counterparts [19]. In addition, allelic deletion was detected specifically in IPF fibroblast, which may be caused by chronic inflammation. This phenomenon was shown to be similar with precancerous lesion, which defective HIPK2 was accumulated during clonal expansion of IPF fibroblast under inflammatory stimulus. Therefore, HIPK2 may represent a novel therapeutic target in pulmonary fibrotic diseases.

Furthermore, in this study we demonstrated for the first time the prevalence and clinical value of $H I P K 2$ : 
A

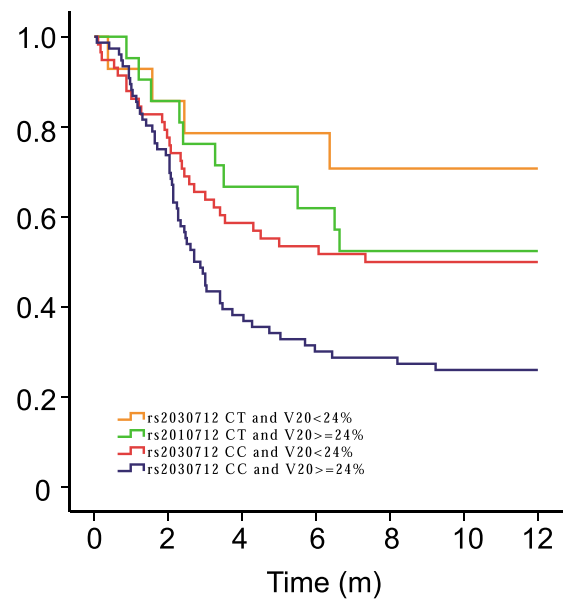

B

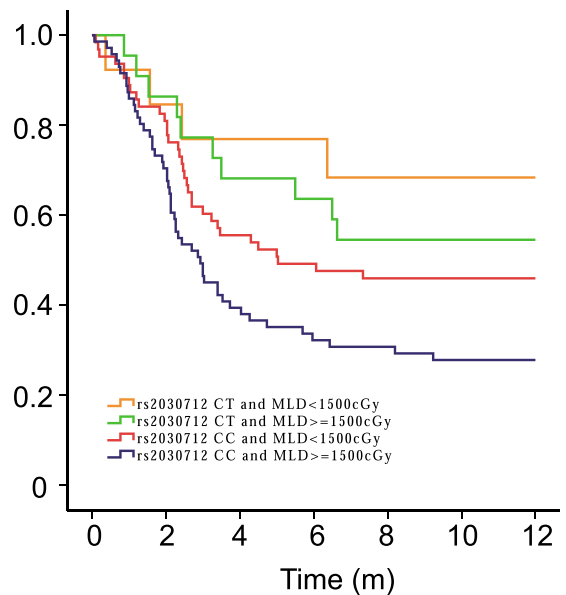

Fig. 2 Kaplan-Meier estimates effect of genotype in HIPK2:rs2030712 and dosimetric parameters on RP-free survival (RP $\geq$ grade 3) (a) HIPK2:rs2030712 and MLD; (b) HIPK2:rs2030712 and $V_{20}$

rs2030712 on RP in independent Chinese Han cohort, and may thus be one of the important predictors of severe $\mathrm{RP}$ before radiotherapy in addition to the radiation dosimetric factors. Those patients with RP susceptibility genotypes will greatly benefit from early prediction and prevention of RP by genotyping before the initiation of RT. And this study will help us to choose the patients without RP susceptibility genotypes and elevate their radiation dose appropriately for a better control of tumor. Especially for the patients with favorable genotypes, elevated MLD and $V_{20}$ will not increase their incidence of severe RP, which could assist the oncologist to adjust the radiation dose personally. Moreover, our findings suggest the possible role of HIPK 2 in the pathogenesis of RP, which will aid in the discovery of target to treat RP in future research.

On the other hand, interstitial lung disease (ILD) is one of the risk factors that have been demonstrated to be related with increased RP incidence [24]. Unfortunately, in this study we didn't include the status of ILD as clinical parameter for cohort analysis, which had potential influence in our conclusion. Therefore, our results still require further validation in expanded cohorts with related ILD status information from different races, since the substantial ethnic variation exist in SNP frequencies. Moreover, HIPK2: rs2030712 warrant further investigation to identify the causative SNPs and their molecular mechanisms. Furthermore, we need to explore the potential role of HIPK2 pathway in the pathogenesis of RP, which would provide novel insight into the treatment of RP.

\section{Conclusions}

In summary, it is the first study to confirm the associations between RP risk and HIPK2: rs2030712, and thus indicated that in addition to the radiation dosimetric factors, HIPK2 SNP can be used as useful predictive biomarker of RP risk before RT. Thus, patients will greatly benefit from early prediction and prevention of RP by genotyping before the initiation of RT. And this study will benefit lung cancer patients receiving radiotherapy since appropriately tailored radiation dose might result in better control of their diseases and lower occurrence and severity of RP.

\section{Abbreviations \\ IPF: Idiopathic pulmonary fibrosis; KPS: Karnofsky performance status; MLD: Mean lung dosage; NSCLC: Non small cell lung cancer; RP: Radiation pneumonitis; RT: Radiotherapy; SCLC: Small cell lung cancer; SNP: Single nucleotide polymorphism}

\section{Acknowledgements}

Not applicable.

\section{Authors' contributions}

TY designed and conducted the major analytical work of the study; YL wrote the draft of the manuscript; QW, YMX and LB contributed in the data collection and statistical analysis. YXL supervised the whole study conduction; All authors have read and approved the final manuscript.

\section{Funding}

This study was funded by National Natural Science Foundation of China (grant No. 81773360 and 81700145).

\section{Availability of data and materials}

The detailed genetic data from our cohort analyzed during the current study are not publicly available due to the private gene information protection policy of our center. But they are available from the corresponding author on reasonable request.

\section{Ethics approval and consent to participate}

This study was approved by the Review Board of Tongji Hospital. Written informed consents were obtained from all patients for the use of their clinical information and for obtaining their blood and DNA.

Consent for publication

Not applicable. 


\section{Competing interests}

The authors declare that they have no competing interests.

\section{Author details}

'Department of Oncology, Tongji Hospital, Huazhong University of Science and Technology, Wuhan, Hubei Province, China. ${ }^{2}$ Department of Hematology, Tongji Hospital, Huazhong University of Science and Technology, Wuhan, Hubei Province, China.

Received: 30 October 2019 Accepted: 30 December 2019 Published online: 08 January 2020

\section{References}

1. Bray F, Ferlay J, Soerjomataram I, et al (2018) Global cancer statistics 2018: GLOBOCAN estimates of incidence and mortality worldwide for 36 cancers in 185 countries. CA Cancer J Clin 68:394-424. https://doi.org/10.3322/caac.21492.

2. Jain V, Berman AT (2018) Radiation pneumonitis: old problem, new tricks. Cancers (Basel) 10:1-16. https://doi.org/10.3390/cancers10070222.

3. Tsujino K, Hashimoto T, Shimada T, et al (2014) Combined analysis of V20, VS5, pulmonary fibrosis score on baseline computed tomography, and patient age improves prediction of severe radiation pneumonitis after concurrent chemoradiotherapy for locally advanced non-small-cell lung cancer. J Thorac Oncol 9:983-990. https://doi.org/10.1097/JTO. 0000000000000187

4. Rodrigues G, Lock M, D'Souza D, et al (2004) Prediction of radiation pneumonitis by dose - volume histogram parameters in lung cancer--a systematic review. Radiother Oncol 71:127-138. https://doi.org/10.1016/j. radonc.2004.02.015.

5. Vogelius IR, Bentzen SM (2012) A literature-based meta-analysis of clinical risk factors for development of radiation induced pneumonitis. Acta Oncol 51:975-983. https://doi.org/10.3109/0284186X.2012.718093.

6. Takeda A, Kunieda E, Ohashi T, et al (2012) Severe COPD is correlated with mild radiation pneumonitis following stereotactic body radiotherapy. Chest 141:858-866. https://doi.org/10.1378/chest.11-1193.

7. Onishi H, Kuriyama K, Yamaguchi M, et al. Concurrent two-dimensional radiotherapy and weekly docetaxel in the treatment of stage III non-small cell lung cancer: a good local response but no good survival due to radiation pneumonitis. Lung Cancer. 2003;40:79-84.

8. Parashar B, Edwards A, Mehta R, et al (2011) Chemotherapy significantly increases the risk of radiation pneumonitis in radiation therapy of advanced lung cancer. Am J Clin Oncol 34:160-164. https://doi.org/10.1097/COC. Ob013e3181d6b40f.

9. Zhao L, Wang L, Ji W, et al (2009) Elevation of plasma TGF-beta1 during radiation therapy predicts radiation-induced lung toxicity in patients with non-small-cell lung cancer: a combined analysis from Beijing and Michigan. Int J Radiat Oncol Biol Phys 74:1385-1390. https://doi.org/10.1016/j.jirobp. 2008.10.065

10. Shi S, Zeng Z, Ye L, et al (2017) Risk factors associated with symptomatic radiation pneumonitis after stereotactic body radiation therapy for stage I non-small cell lung Cancer. Technol Cancer Res Treat 16:316-320. https://doi.org/10.1177/1533034616661665

11. Tang Y, Liu B, Li J, et al (2016) Genetic variants in PI3K/AKT pathway are associated with severe radiation pneumonitis in lung cancer patients treated with radiation therapy. Cancer Med 5:24-32. https://doi.org/10.1002/ cam4.564.

12. Yi M, Tang Y, Liu B, et al (2016) Genetic variants in the ITGB6 gene is associated with the risk of radiation pneumonitis in lung cancer patients treated with thoracic radiation therapy. Tumour Biol 37:3469-3477. https://doi.org/10.1007/s13277-015-4171-y.

13. Liu B, Tang Y, Yi M, et al (2017) Genetic variants in the plasminogen activator inhibitor-1 gene are associated with an increased risk of radiation pneumonitis in lung cancer patients. Cancer Med 6:681-688. https://doi.org/ 10.1002/cam4.1011.

14. Liu B, Yi M, Tang Y, et al (2016) MMP-1 promoter polymorphism is associated with risk of radiation-induced lung injury in lung cancer patients treated with radiotherapy. Oncotarget 7:70175-70184. https://doi.org/10. 18632/oncotarget.12164

15. Xiao Y, Yuan X, Qiu H, Li Q. Single-nucleotide polymorphisms of TGFbeta1 and ATM associated with radiation-induced pneumonitis: a prospective cohort study of thoracic cancer patients in China. Int J Clin Exp Med. 2015;8: 16403-13.
16. Wen J, Liu H, Wang L, et al (2018) Potentially functional variants of ATG16L2 predict radiation pneumonitis and outcomes in patients with non-small cell lung Cancer after definitive radiotherapy. J Thorac Oncol 13:660-675. https://doi.org/10.1016/j.jtho.2018.01.028.

17. Calzado MA, De La Vega L, Munoz E, Schmitz ML (2009) From top to bottom: the two faces of HIPK2 for regulation of the hypoxic response. Cell Cycle 8:1659-1664. https://doi.org/10.4161/cc.8.11.8597.

18. Rinaldo C, Prodosmo A, Siepi F, Soddu S (2007) HIPK2: a multitalented partner for transcription factors in DNA damage response and development. Biochem Cell Biol 85:411-418. https://doi.org/10.1139/007-071.

19. Ricci A, Cherubini E, Ulivieri A, et al (2013) Homeodomain-interacting protein kinase2 in human idiopathic pulmonary fibrosis. J Cell Physiol 228: 235-241. https://doi.org/10.1002/jcp.24129.

20. Zywiec J, Kiliś-Pstrusińska K, Gumprecht J, et al. No associations between rs2030712 and rs7456421 single nucleotide polymorphisms of HIPK2 gene and prevalence of chronic kidney disease. Results of a family-based study. Ann Agric Environ Med. 2013;20:131-4.

21. Lierova A, Jelicova M, Nemcova M, et al (2018) Cytokines and radiationinduced pulmonary injuries. J Radiat Res 59:709-753. https://doi.org/10. 1093/jrr/rry067.

22. Fan Y, Wang N, Chuang P, He JC (2014) Role of HIPK2 in kidney fibrosis. Kidney Int Suppl 4:97-101. https://doi.org/10.1038/kisup.2014.18.

23. Jin Y, Ratnam K, Chuang PY, et al (2012) A systems approach identifies HIPK2 as a key regulator of kidney fibrosis. Nat Med 18:580-588. https://doi.org/10.1038/nm.2685.

24. Tamiya A, Tamiya M, Nakahama K, et al (2017) Correlation of radiation pneumonitis history before nivolumab with onset of interstitial lung disease and progression-free survival of patients with pre-treated advanced nonsmall cell lung cancer. Anticancer Res 37:5199-5205. https://doi.org/10. 21873/anticanres.11943

\section{Publisher's Note}

Springer Nature remains neutral with regard to jurisdictional claims in published maps and institutional affiliations.

Ready to submit your research? Choose BMC and benefit from

- fast, convenient online submission

- thorough peer review by experienced researchers in your field

- rapid publication on acceptance

- support for research data, including large and complex data types

- gold Open Access which fosters wider collaboration and increased citations

- maximum visibility for your research: over $100 \mathrm{M}$ website views per year

At BMC, research is always in progress.

Learn more biomedcentral.com/submissions 